\title{
Gambaran Pharmacovigilance dan Hubungan Faktor yang Mempengaruhi Reaksi Obat yang Tidak Diinginkan (ROTD) Pada Pasien Peresepan Obat Tuberculosis di Rumah Sakit Islam Sultan Agung Semarang \\ Pharmacovigilance Overview and Affecting Factor Relation of Unwanted Drug Reactions in Tuberculosic Drug Patients at Islamic Sultan Agung Hospital
}

\author{
Abdur Rosyid $^{1 *}$, Farroh Bintang Sabiti ${ }^{1}$, Destiara Firstie Roshani ${ }^{1}$ \\ 1 Universitas Islam Sultan Agung Semarang, \\ email : rosyid@unissula.ac.id
}

\begin{abstract}
Abstrak
Penyakit Tuberkulosis (TB) saat ini masih menjadi permasalahan global yang semakin bertambah setiap tahunnya. Penyakit TB adalah salah satu dari 10 penyakit yang menyebabkan kematian di seluruh dunia.

Rancangan penelitian ini merupakan suatu pengamatan kualitatif dengan pendekatan desain secara prospektif cross sectional. Penelitian dilakukan di Rumah Sakit Islam Sultan Agung Semarang mulai bulan Februari sampai dengan jumlah sampel yang diinginkan.

Dari subyek pasien penyakit tuberkulosis dengan jumlah 92 pasien. Jumlah pasien yang mengalami kejadian ROTD dengan kategori meragukan yaitu 56 pasien $(60,9 \%)$, pada pasien yang mengalami kejadian ROTD dengan kategori mungkin yaitu 32 pasien $(34,8 \%)$, dan pada pasien kejadian ROTD dengan kategori besar kemungkinan yaitu 4 pasien (4,3\%). Terdapat hubungan bermakna antara usia dengan kejadian ROTD nilai signifikansi 0,000 dan hubungan bermakna antara jenis kelamin dengan kejadian ROTD dengan nilai signifikansi 0,000.
\end{abstract}

Keyword : Obat Tuberkulosis, Reaksi Obat Tidak Diinginkan

\section{ABSTRACT}

Tuberculosis (TB) is still a growing global problem every year. TB disease is one of the 10 diseases that cause death worldwide.

The design of this study is a qualitative observation with a prospective cross sectional design approach. The research was conducted at Sultan Agung Islamic Hospital, Semarang, from February to the desired sample size.

From the subjects of tuberculosis patients with 92 patients. The number of patients experiencing ROTD with a dubious category was 56 patients $(60.9 \%)$, in patients who experienced ROTD events with a possible category of 32 patients (34.8\%), and in patients with ROTD with a category of probable 4 patients $(4.3 \%)$. There is a significant relationship between age and ROTD incidence of a significance value of 0,000 and a significant relationship between sexes with ROTD incidence with a significance value of 0,000 .

Keyword : Therapy Tuberculosis, Adverse Drug Reactions

\section{PENDAHULUAN}

Penyakit Tuberkulosis (TB) saat ini masih menjadi permasalahan global yang semakin bertambah setiap tahunnya.Penyakit TB adalah salah satu dari 10 penyakit yang menyebabkan kematian di seluruh dunia (WHO, 2017).Tuberkulosis(TB) merupakan penyakit menular yang disebabkan oleh bakteri Mycobacterium tuberculosis.Bakteri Mycobacterium tuberculosis ditularkan melalui percikan dahak (dorplet) dari penderita tuberkulosis kepada individu yang rentan. Sebagian besar kuman Mycobacterium tuberculosis menyerang 
paru, namun dapat juga menyerang organ lain seperti pleura, selaput otak, kulit, kelenjar limfe, tulang, sendi, usus, sistem urogenital, dan lain-lain (Depkes RI, 2009). Kuman ini berbentuk batang yang mempunyai sifat khusus yaitu tahan terhadap asam pada pewarnaan, sehingga disebut pula sebagai Basil Tahan Asam (BTA) (Depkes RI, 2008).Penyakit ini bila tidak diobati dengan tuntas dapat menimbulkan komplikasi yang membahayakan dan dapat menyebabkan kematian (Kemenkes RI, 2015). Pada tahun 2016 sebanyak 1,7 juta manusia di dunia meninggal dunia karena TB. Diperkirakan ada sekitar 10,4 juta kasus TB baru di seluruh dunia, dengan jumlah 6,7 juta laki-laki, 3,2 juta perempuan dan 1 juta adalah anak (WHO, 2017). Tujuh negara penyumbang kasus TB sebanyak 64\% yaitu India, China, Filipina, Pakistan, Nigeria, Afrika Selatan dan salah satunya adalah Indonesia (WHO, 2017). Jumlah penderita penyakit tuberkulosis (TB) di Indonesia merupakan negara dengan pasien TB terbanyak ke-4 di dunia setelah India, Cina, dan Afrika Selatan. Diperkirakan jumlah pasien TB di Indonesia sekitar 5,7\% dari total jumlah pasien TB dunia, dengan setiap tahun ada 450.000 kasus baru dan 65.000 kematian (Kemenkes, 2013). Pengobatan kasus Tuberkulosis merupakan salah satu strategi utama pengendalian Tuberkulosis karena dapat memutuskan rantai penularan. Meskipun Program Pengendalian TB Nasional telah berhasil mencapai target angka penemuan dan angka kesembuhan, penatalaksanaan TB di sebagian besar rumah sakit dan praktik swasta belum sesuai dengan strategi Directly Observed Treatment Shortcourse (DOTS) dan penerapan standar pelayanan berdasar International Standards for Tuberculosis Care (ISTC).

Pada awalnya, penerapan strategi DOTS di Indonesia hanya dilaksanakan di pusat kesehatan masyarakat (puskesmas). Dengan seiring berjalannya waktu, strategi DOTS mulai dikembangkan di Balai Kesehatan Paru Masyarakat (BKPM) dan rumah sakit baik rumah sakit pemerintah maupun rumah sakit swasta. (Kemenkes, 2013). Pengobatan pada pasien TB perlu dilakukan hingga tuntas agar tercapai kesembuhan pasien dan tidak menyebabkan resistensi pengobatan, Pasien TB yang menjalani pengobatan menggunakan lebih dari satu obat antiTB secara bersamaan dan rejimen yang berlangsung dari beberapa bulan sampai 2 tahun atau lebih akan meningkatkan kemungkinan adanya Reaksi Obat Yang Tidak Dikehendaki (ROTD), beberapa diantaranya sangat parah dan efek samping yang timbul menyebabkan pasien berhenti melakukan pengobatan (Sreekanth, 2015). Hal ini perlu adanya suatu ilmu dan aktifitas yang berhubungan dengan deteksi penilaian, pemahaman dan pencegahan dari efek samping obat atau masalah lain yang berhubungan dengan obat (DRP) yang disebut dengan Pharmacovigilance (WHO, 2012). Penelitian pharmacovigilance yang dilakukan oleh Sreekanth (2015) di Tertiary care hospital menyimpulkan bahwa obat anti TB dapat menyebabkan efek samping yang signifikan baik dalam kuantitas maupun kualitas, terutama orang Asia yang dapat menyebabkan 
keparahan seperti hepatitis. Penelitian lain yang dilakukan oleh Shamiya et al (2015) menyebutkan bahwa ROTD terbanyak pada pasien TB yaitu usia 4150 tahun, selain itu ROTD lebih sering terjadi pada pria. ROTD yang terjadi menyebabkan gangguan gastrointestinal. Tujuan dari Pharmacovigilance untuk meningkatkan keamanan dan keselamatan pasien terkait pengobatan yang didapatnya, dari kemungkinan kejadian ROTD, yang bersifat individual dan menganalisa pharmacovigilance yang meliputi ADR dan interaksi obat yang terjadi pada pasien Tuberkulosis di Rumah Sakit Islam Sultan Agung Semarang dan juga diharapkan penelitian ini dapat meningkatkan pelayanan dan terapi penggunaan obat secara aman, benar, dan efektif.

\section{METODE PENELITIAN}

\section{Alat dan Bahan}

Rancangan penelitian ini merupakan suatu pengamatan kualitatif dengan pendekatan desain secara prospektif cross sectional. Penelitian dilakukan di Rumah Sakit Islam Sultan Agung Semarang mulai bulan Februari sampai dengan jumlah sampel yang diinginkan.

Alat yang digunakan dalam penelitian ini adalah kuisoner penelitian salah satunya berupa terapi pengobatan yang diresepkan, elemen kejadian reaksi obat yang tidak diinginkan (ROTD) . Sedangkan data kejadian ROTD dapat ditelusur amati pada pustaka Drug Information Handbook
(DIH) 2014 dan Meyler's Side Effect of Drugs. Kemudian probabilitas kejadian ROTD sebagai konfirmasi kausalitas ROTD dinilai dengan naranjo scale yaitu dengan deskripsi pasti terjadi ROTD, Kemungkinan terjadi ROTD dan meragukan terjadi ROTD. Pengumpulan data dilakukan di Rumah Sakit Islam Sultan Agung Semarang dengan periode mulai bulan Februari tahun 2018 sampai dengan jumlah sampel tercukupi. Pengisian instrumen penelitian dengan lembar kuisoner dan diukur dengan algoritma Naranjo.

\section{HASIL DAN PEMBAHASAN}

Berdasarkan hasil diatas dapat dijelaskan bahwa pasien dengan usia 20-50 tahun terdapat sebanyak 61 $(66,3 \%)$. Pasien dengan usia antara $51-$ 60 tahun terdapat $25(27,2 \%)$ dan pasien dengan usia diatas 60 tahun terdapat sejumlah 6 (6,5\%). Pasien TB yang diteliti dalam penelitian ini sebagian besar berjenis kelamin laki-laki sebanyak 59 (64,1\%) dan pasien perempuan terdapat sebanyak 33 $(35,9 \%)$. Karakteristik responden berdasarkan pekerjaan didapati sebagian besar pasien bekerja sebagai IRT sebanyak 21 (22,8\%), pasien sebagai pedagang dan mahasiswa masing-masing $13(14,1)$, pasien yang tidak bekerja terdapat 11 (12\%), pasien yang bekerja sebagai petani terdapat 10 $(10,9 \%)$, wiraswasta terdapat 9 , swasta terdapat $8(8,7 \%)$ dan pasien yang bekerja sebagai PNS terdapat 5 (5,4\%). 
Tabel 1. Karakteristik responden berdasarkan usia, jenis kelamin, pekerjaan

\begin{tabular}{lcc}
\hline Keterangan & $\mathbf{N}$ & Persentase \\
\hline 20-50 tahun & 61 & 66,3 \\
51-60 tahun & 25 & 27,2 \\
Diatas 60 tahun & 6 & 6,5 \\
$\begin{array}{l}\text { Jenis Kelamin } \\
\text { Laki-laki }\end{array}$ & 59 & 64,1 \\
Perempuan & 33 & 35,9 \\
Pekerjaan & & \\
Wiraswasta & 9 & 9,8 \\
Swasta & 8 & 8,7 \\
PNS & 5 & 5,4 \\
Petani & 10 & 10,9 \\
Pelajar/mahasiswa & 13 & 14,1 \\
Pedagang & 13 & 14,1 \\
Nelayan & 2 & 2,2 \\
IRT & 21 & 22,8 \\
Tidak bekerja & 11 & 12,0 \\
Total & 92 & 100 \\
\hline
\end{tabular}

Tabel 2. Karakteristik Responden berdasarkan durasi menderita, manifestasi, obat TB

\begin{tabular}{lcc}
\hline Karakteritik & N & $\%$ \\
\hline Durasi Menderita & 73 & \\
0-3 tahun & 15 & 79,3 \\
4-7 tahun & 4 & 16,3 \\
diatas 7 tahun & & 4,3 \\
\hline Penyakit Penyerta & 6 & 6,5 \\
DM & 2 & 2,2 \\
HIV & 84 & 91,3 \\
\hline tidak ada & & \\
\hline Golongan Obat TB & 45 & 48,9 \\
Oat lintensif K.I & 45 & 48,9 \\
Oat lanjutan & 2 & 2,2 \\
Oat intensif K.II & & \\
\hline Manifestasi & 6 & 6,5 \\
Gatal & 8 & 8,7 \\
Gatal-pusing & 10 & 10,9 \\
Kesemutan & 7 & 7,6 \\
Mual & 13 & 14,1 \\
Mual-gatal & 7 & 7,6 \\
Mual-pusing & 19 & 20,7 \\
Nyeri sendi & 11 & 12,0 \\
Perubahan warna urin & 11 & 12,0 \\
\hline Pusing & 92 & $100 \%$ \\
\hline Total & & \\
\hline
\end{tabular}


Berdasarkan Tabel 2. Terdapat 73 pasien dengan durasi menderita TB selama 0-3 tahun terdapat $73(79,3 \%)$, pasien dengan lama menderita TB 4-7 tahun terdapat 15 responden dan pasien yang menderita TB diatas 7 tahun terdapat 4 pasien.

Pasien TB dengan penyakit penyerta DM terdapat $6(6,5 \%)$ responden, dengan penyakit penyerta HIV terdapat $2(2,2 \%)$ responden dan tidak ada penyakit penyerta terdapat 84 $(91,3 \%)$ responden.
Pasien TB dengan obat terapi OAT intensif kategori I terdapat 45 responden, OAT lanjutan kategori I terdapat 45 responden dan terdapat 2 responden pada pasien yang mendapat terapi OAT intensif kategori II.

Pasien dengan manifestasi nyeri sendi terdapat 19 responden. Pasien dengan manifestasi mual -gatal terdapat 13 responden. Pasien dengan manifestasi perubahan warna urin dan pusing terdapat masing-masing 11 pasien, 10 pasien dengan manifestasi kesemutan, 8 pasien dengan manifestasi gatal pusing.

Tabel 3. Karakteristik Responden Berdasarkan Kejadian Naranjo

\begin{tabular}{lcc}
\hline Kejadian Naranjo & $\mathbf{N}$ & $\%$ \\
\hline Meragukan & 56 & 60,9 \\
Mungkin & 32 & 34,8 \\
Besar Kemungkinan & 4 & 4,3 \\
Total & 92 & 100,0 \\
\hline
\end{tabular}

Tabel. 4. Karakteristik Kategori Obat Skor Berdasarkan Kejadian naranjo

\begin{tabular}{cllccc}
\hline $\begin{array}{c}\text { Subjek } \\
\text { Penelitian }\end{array}$ & \multicolumn{1}{c}{ Terapi Obat } & Manifestasi & Skor & Kategori & $\begin{array}{c}\text { Obat } \\
\text { Diduga }\end{array}$ \\
\hline 1 & $\begin{array}{l}\text { OAT Intensif } \\
\text { Kategori 1 kombinasi } \\
\text { Glimipirid }\end{array}$ & $\begin{array}{l}\text { Perubahan } \\
\text { Warna Urin }\end{array}$ & 3 & Mungkin & HRZE \\
2 & $\begin{array}{l}\text { OAT Intensif } \\
\text { Kategori 1 kombinasi } \\
\text { FDC ARV }\end{array}$ & Gatal Pusing & 7 & $\begin{array}{c}\text { Kesar } \\
\text { kinang }\end{array}$ & HRZE \\
3 & $\begin{array}{l}\text { OAT Intensif } \\
\text { Kategori 1 }\end{array}$ & Nyeri Sendi & 5 & Mungkin & HRZE \\
\hline
\end{tabular}

Berdasarkan Tabel 3. diatas dapat diketahui pasien dengan kejadian ROTD meragukan berdasarkan Algoritma naranjo terdapat $56(60,9 \%)$ responden, pasien dengan kejadian ROTD mungkin berdasarkan kuesioner naranjo terdapat $32(34,8 \%)$ dan terdapat $4(4,3 \%)$ pasien dengan kejadian ROTD besar kemungkinan berdasarkan penilaian naranjo.

Sejumlah 3 subyek penelitian melaporkan telah mengalami kejadian ROTD dengan kategori mungkin dan besar kemungkinan. Identifikasi 
terhadap pernyataan subyek penelitian tersebut berdasarkan scoring terhadap hasil wawancara tahap akhir dengan panduan algoritma Naranjo. Subyek penelitian 1 memperoleh terapi obatobat OAT intensif kategori I. Pernyataan subyek penelitian menyatakan bahwa setelah menggunakan obat-obat tersebut, subyek penelitian mengalami perubahan warna urin. Subyek penelitian 2 memperoleh terapi obatobat OAT intensif kategori I. Pernyataan subyek penelitian menyatakan bahwa setelah menggunakan obat-obat tersebut, subyek penelitian mengalami gatal, pusing.

Subyek penelitian 3 memperoleh terapi obat-obat OAT intensif kategori I. Pernyataan subyek penelitian menyatakan bahwa setelah menggunakan obat-obat tersebut, subyek penelitian mengalami nyeri sendi.

Tabel 5. Hubungan Usia dengan kejadian ROTD berdasarkan Naranjo

\begin{tabular}{llcccccc}
\hline Usia & \multicolumn{1}{c}{ ROTD } & N & Rerata \pm SD & p & $\begin{array}{c}\boldsymbol{r} \\
\text { correlatio } \\
\boldsymbol{n}\end{array}$ \\
\hline $20-50$ & Meragukan & 46 & 1,28 & $\mathbf{\pm}$ &, 521 & .000 & 0.369 \\
& $\begin{array}{l}\text { Mungkin } \\
\text { Besar }\end{array}$ & 13 & & & & & \\
& Kemungkinan & 2 & & & & & \\
\hline $51-60$ & Meragukan & 8 & 1,72 & $\mathbf{\pm}$ &, 542 & & \\
& Mungkin & 16 & & & & & \\
& Besar & 1 & & & & & \\
& Kemungkinan & 1 & & & & & \\
\hline$>60$ & Meragukan & 2 & 1,83 & $\mathbf{\pm}$ &, 753 & & \\
& Mungkin & 3 & & & & & \\
& Besar & 1 & & & & \\
& Kemungkinan & & & & & \\
\hline Total & & 92 & 1,43 & $\mathbf{\pm}, 580$ & & \\
\hline
\end{tabular}

Tabel.5. Menunjukan bahwa pasien berusia 20-50 tahun terdapat pasien dengan kejadian ROTD meragukan adalah terdapat 46 pasien, 13 pasien dengan ROTD mungkin, dan 2 pasien pada ROTD besar kemungkinan dengan rerata \pm sd menunjukan nilai $1,28 \pm 0,521$. Pada rentang usia 51-60 tahun terdapat 8 pasein pada kategori ROTD meragukan, 16 pasien pada rentang ROTD mungkin dan terdapat 1 responden pada rentang ROTD besar kemungkinan. dengan rerata \pm sd menunjukan nilai $1,72 \pm$ 0,542 .

Pada rentang usia lebih dari 60 tahun terdapat 2 pasien pada kategori ROTD meragukan 3 pasien pada rentang ROTD mungkin dan 1 pasien pada kategori besar kemungkinan dengan rerata \pm sd menunjukan nilai $1,83 \pm 0,753$. Berdasarkan uji hubungan 
umur dengan kejadian ROTD dengan uji Pearson Chi Square didapati nilai signifikansi 0,000 dengan nilai $r=0,369$ yang berada pada rentang kekuatan hubungan lemah dengan nilai $r$ antara 0,30-0,49. Dengan demikian dapat disimpulkan bahwa terdapat hubungan antara umur dengan kejadian ROTD dengan hubungan kekuatan lemah di mana dengan meningkatnya usia pasien akan meningkatkan resiko ROTD pada pasien.

Tabel. 6. Hubungan Jenis Kelamin dengan Kejadian ROTD berdasarkan Naranjo

\begin{tabular}{llcccccc}
\hline Jenis Kelamin & \multicolumn{1}{c}{ ROTD } & N & \multicolumn{2}{c}{ Rerata \pm SD } & $\boldsymbol{p}$ & $\begin{array}{c}\boldsymbol{r} \\
\text { correlation }\end{array}$ \\
\hline Perempuan & Meragukan & 43 & 1,28 & $\mathbf{\pm}$ &, 493 & .000 & 0.340 \\
& $\begin{array}{l}\text { Mungkin } \\
\text { Besar }\end{array}$ & 15 & & & & & \\
& Kemungkinan & 1 & & & & & \\
\hline Laki-laki & Meragukan & 13 & 1,69 & $\mathbf{\pm}$ &, 637 & & \\
& Mungkin & 17 & & & & & \\
& Besar & 3 & & & & & \\
& Kemungkinan & 3 & & & & \\
\hline Total & 92 & 1,43 & $\mathbf{\pm}, 580$ & & \\
\hline
\end{tabular}

Pada Tabel.6 Menunjukan hasil uji menunjukan data di mana terdapat 43 pasien perempuan pada kategori ROTD meragukan, 15 pasien pada kategori ROTD mungkin dan 1 pasien perempuan pada kategori besar kemungkinan dengan rerata \pm sd menunjukan nilai $1,28 \pm 0,493$.

Hasil uji menunjukan hasil di mana terdapat 13 pasien laki-laki pada kategori ROTD meragukan, 17 pasien pada kategori mungkin dan 3 pasien laki-laki pada kategori ROTD besar kemungkinan dengan rerata \pm sd menunjukan nilai 1,69 0,637.

Berdasarkan uji hubungan jenis kelamin dengan kejadian ROTD dengan uji Pearson Chi Square didapati nilai signifikansi 0,000 dengan nilai $r=$ 0,340yang berada pada rentang kekuatan hubungan lemah dengan nilai $r$ antara 0,30-0,49. Dengan demikian dapat disimpulkan bahwa terdapat hubungan antara jenis kelamin dengan kejadian ROTD dengan hubungan kekuatan lemah. pada penelitian ini didapati hasil dimana perempuan beresiko mengalami ROTD dibandingkan laki-laki.

\section{KESIMPULAN}

Berdasarkan hasil penelitian terdapat hubungan antara usia dan jenis kelamin dengan kejadian ROTD memiliki hubungan kekuatan lemah yang berada pada rentang kekuatan hubungan dengan nilai $c$ antara $0,30-$ 0,49 .

\section{DAFTAR PUSTAKA}

Depkes RI, 2009, Pedoman Nasional Penanggulangan Tuberkulosis Paru, Depkes RI, Jakarta

Depkes RI, 2008, Pedoman Naisonal Penanggulangan Tuberkulosis, Cetakan Kedua, Depkes RI, Jakarta. 
Kemenkes RI. 2015. Infodatin Tuberkulosis temukan Obati sampai Sembuh. Jakarta.

WHO, 2002. Safety of Medicines A Guide to Detecting and Reporting Adverse Drug Reactions. Geneva, World Health Nation.

WHO, 2012.A practical Handbook on the Pharmacovigilance of medicines used in the treatment of tuberculosis, WHO, Perancis.

WHO, 2017, Tuberculosis Global Tuberculosis Report 2017, WHO. 